\title{
How to Overcome Complexities of Interdisciplinary Communication? Translation from One Disciplinary Language into Another for Interdisciplinary Course Design
}

\author{
Tatyana A. Martynova ${ }^{1, *}$, Elena V. Orlova1, Elena M. Kitaeva ${ }^{2}$ \\ ${ }^{1}$ Department of the Languages for Academic and Business Communication, Faculty of Foreign Languages, \\ St Petersburg State University, Russia \\ ${ }^{2}$ Department of the English Language for Psychologists, Faculty of Foreign Languages, \\ St Petersburg State University, Russia
}

Received December 30, 2019; Revised February 25, 2020; Accepted March 12, 2020

Copyright $\odot 2020$ by authors, all rights reserved. Authors agree that this article remains permanently open access under the terms of the Creative Commons Attribution License 4.0 International License

\begin{abstract}
This paper presents the analysis of the first stage of interdisciplinary course design, which is aimed at the development of the communicative competence across disciplines in business education. The complexities of interdisciplinary communication caused by team members' diverse professional backgrounds, areas of expertise, organizational contexts, life experiences and unique disciplinary languages need to be under control on the way to achieve the intended goals. To foster the interdisciplinary course outcomes, we modeled the translation process from one disciplinary perspective with its scientific language into a language that is understandable to members of different disciplinary expertise. The model stems from the definition of translation as an intralingual transformation process inherent in communication of diverse disciplinary groups in order to co-create new interdisciplinary meaning and achieve the shared goals. It was applied to translation of learning goals and objectives from the language of the business and management course into the language of the English language and communication course to facilitate the process of interdisciplinary collaboration among the team members. The effect of the translation process lay in the team members' better understanding of the integration principle of the interdisciplinary course. This study can give impetus to further research to investigate the process of intralingual translation as a social practice and factors of successful interdisciplinary communication.
\end{abstract}

Keywords Interdisciplinary Communication, Interdisciplinary Course, Disciplinary Perspective, Translation, Language and Communication

\section{Introduction}

In 2017 the instructors of language and communication courses and the lecturers of business and management disciplines at St. Petersburg State University, Russia, formed a multidisciplinary team with the purpose of designing an interdisciplinary course at the intersection of the English language (as a foreign language), communication and subject-specific disciplines for business and management students of a bachelor program. The interdisciplinary course design required collaboration and contributions from all team members in the process of continuous discussions about how to integrate knowledge areas with different specific nature in order to enhance the development of the core communicative competence and subject-specific competences across the disciplines.

The collaboration process extended for the time and revealed communication complexities due to high diversity of membership in the project. The main barriers that added complexity to effective collaboration were members' attempts to stay within their disciplinary boundaries when crossing them in order to grasp another discipline perspective, the habit of expressing thoughts in a professional language unique to the areas of expertise and unfamiliar to other members and, as a result, critical judgments about the integration prospects.

The challenges of academic collaboration for the purpose of interdisciplinary course development may occur at every stage of the process when members of a 
team identify complex problems and disciplines with diverse perspectives to be integrated, set the learning goal and objectives, select appropriate methods and materials, sequence the course modules and design assignments. The collaboration of interdisciplinary course designers does not finish with preparation of a syllabus and it usually extends for the following tasks of team teaching or teaching separate sections of the course, evaluation of the integrated course implementation and upgrading it to new needs.

The scope of communication challenges needs proper consideration at the outset of academic interdisciplinary endeavor, since they might prevent accomplishing the intended goals of a project. Participants may differ in their values and motivations shaped by their unique areas of expertise, organizational contexts, or life experiences. Communication problems can also occur due to members' use of specific terminology or scientific language.

Communication challenges can be eliminated if team members are aware of factors of successful communication and are able and willing to go beyond the disciplinary boundaries and integrate their own perspective into a bigger holistic picture. To this end, identification and description of features that characterize successful communication across disciplines turn out to be as important as specification of potential communication barriers or breakdowns.

We assume that language and communication instructors and instructors in the area of business and management might perceive, formulate and translate information diversely, from the perspectives of their disciplinary expertise and individual professional backgrounds that result in decision making. The way how individuals put across their thoughts and communicate the message is both messenger-specific and audience-specific. It takes a variety of forms based on the context of communication, levels of team members' awareness, their professional backgrounds as well as differences in patterns of language usage in various disciplines.

We hypothesize that interdisciplinary team members will achieve the intended goals faster if they know how to translate from one disciplinary language into another and communicate ideas from one professional group to another. A disciplinary language means a sublanguage used by experts from a particular disciplinary field. It is characterized by its professional terminology that can convey different meanings for experts of another discipline. This study draws on the interdisciplinary approach to translation that advocates spanning of boundaries among disciplines and identifying entities that exist on the boundaries of already-existing fields of knowledge.

To foster interdisciplinary communication, team members need to be able to translate one disciplinary perspective with its scientific language into a language that is understandable to professionals of a different disciplinary expertise.

\section{Literature Review}

\subsection{Intricacies of Interdisciplinary Communication}

A growing body of literature explores the challenges of interdisciplinary research collaboration at individual and group levels in different fields of knowledge and ways how to overcome them: Eigenbrode et al. [1], Cummings et al. [2], Cooke \& Hilton [3], Dielman [4], Keestra [5], Lash-Marshal et al. [6], Locker [7] and Welsh [8].

Cooke and Hilton [3] contend that a high level diversity in scientific collaboration can be more challenging than solo science. Differences in values and motivations among participants of a research team shaped by their unique areas of expertise, organizational contexts, or life experiences can weaken identification with the group [2]. According to Keestra [5], one of the main challenges in interdisciplinary collaboration is 'developing adequacy in another discipline, an understanding of each relevant discipline's cognitive map sufficient to identify its perspective on the problem, epistemology, assumptions, concepts, theories and methods' as well as combining cognitive maps'.

Adopting a different research paradigm makes us take different assumptions about the nature of reality and how we can come to know it. As a result, we tend to disagree about what data is relevant, what kind of analysis is convincing and what research questions are important [7]. Welsh elaborates on the difficulties of psycho-social nature that interdisciplinarians encounter. He claims that cognitive dissonance is a fundamental mechanism of conflict affecting academic experts who have not developed the professional habit of mind to give "equal weight to ideas outside of their familiar field' [8]. Apart from cognitive dissonance, interdisciplinarians should take into account the 'deep-seated psychological instinct' of confirmation bias when working out an integrative solution to a complex problem. He warns interdisciplinary team members against making 'snap judgments without sufficient evidence' and defending 'our belief systems without justification' [8].

Communication problems in collaboration can also occur due to members' use of specific terminology or scientific language that is unique to their area of expertise, and therefore, unfamiliar to other members. The unique languages of the disciplines reflect deeper differences in underlying assumptions, epistemologies (ways of knowing), philosophies, and approaches to science and societal problems [1].

The scope of disciplinary barriers to effective research collaboration has been classified as complexities at microand macro-levels [6]. Interestingly, the main problems at both levels are lack of trust (rivalry) and pre-existing biases or reputations of specific individuals and institutions. The scholars emphasize necessity of identification of barriers to collaboration at an early stage 
as well as development of strategies to overcome them and facilitate the success of interdisciplinary endeavors.

\subsection{Overcoming Interdisciplinary Challenges}

The nature of the above-mentioned challenges of interdisciplinary collaboration suggests the moves how to address them.

Mansilla points out that taking perspective is 'a human capacity evolutionary engrained in our human biology' [9]. Another human ability is compassion and empathy that can be turned into a strategy to facilitate interdisciplinary collaboration as we aim to find the common ground through personal interaction [8].

To solve communication problems, Repko, Szostak and Buchberger [10] propose to put them into a larger context and consider conflicting issues through a holistic picture reflecting on individual pre-conceptions and values. According to Dielman [4], we can hardly overcome communication barriers created by disciplinary boundaries until we 'contextualize science in the framework of cultural ideas and concepts, values, emotions and visions, rather than in the framework of technology, economics and politics. This approach stems from the way of thinking that 'knowing is a constructive act of creating a particular reality out of many realities' and the created reality depends on us, on our imagination, motivation, actions and behavior. We cannot possibly achieve one single way of seeing reality as the reality is discontinuous and multilayered; so, at a certain period of time we deal with a certain part of reality (an organization, team) that can be seen and understood. Working across disciplines, experts need to allow for multiple narratives and storylines and reflect on polyphonic voices.

Team members can eliminate interdisciplinary collaboration problems if they are aware of factors of successful communication: respectful and constructive conversation, formalizing expectations at the start, regular interactions to clarify goals, roles and tasks, 'appreciative inquiry' where team members learn the strengths of other team members and see through their eyes [11]. Participants of an interdisciplinary team can collaboratively define principles and actions of work. Lash-Marshall, Nomura, Eck and Hirsch [6] identified 3 principles of successful interdisciplinary collaboration: to cultivate trust and respect for intellectual property, be an active participant and generate shared values.

On the top of that, in most challenging situations the strategy of undecidability can be adopted at different stages of interdisciplinary collaboration Welsh [8]. For example, when formulating a problem with its nuances being implicit, one needs to be open-minded and withdraw from quick and poor decisions.

At the same time, there is a need in practical tools to instigate interdisciplinary work. Translation is one of communication strategies that helps experts with diverse disciplinary backgrounds overcome the hurdles of interdisciplinary collaboration in the process of investigating relevant disciplinary perspectives and searching for the links between them.

\subsection{Translation: The Concept and Process of Transformation}

The concept of translation is in the focus of multiple disciplines - linguistics, sociology, organization studies, etc.

In social sciences, the concept of translation is portrayed as a social practice when individuals are negotiating meanings and interests to achieve the intended goal [12]. In this process they often resort to persuasion rhetoric, power play and strategic maneuvers [13]. As such, translation conveys political meaning. Besides, translation has a geometric dimension which means movement and development of knowledge across different groups and organizations. While its moving, the meaning undergoes transformations resulting in unique translations which depend on specific characteristics of the context. This feature of translation is known as s semiotic meaning.

This conceptualization of translation is also known as a knowledge-based perspective: 'a boundary-spanning activity to ensure the effective flow of critical information and domain-specific knowledge across organizational boundaries' [14]. It is emphasized that translation goes beyond knowledge transfer; it embraces understanding of what knowledge means in the recipient context.

Latour [15] portrays translation as a process of 'continuous transformation' which may result in 'a chain of unique translations depending on the distinct characteristics of the context.' Likewise, Lecomte [16] emphasizes that 'the translation process is much better defined as a creative activity, which shapes a new reality.' Translation stands for 'a re-conceptualization of meanings from a linguistic and cultural semiotic source system into a target semiotic system. It is a reconfiguration and the translator is a 'reconfiguration agent.'

\subsection{Translation for Interdisciplinary Communication}

For interdisciplinary collaboration purposes, translation is an intralingual process of communication, rather than transmission of information from one language as a semiotic system into another language. This conceptualization is aligned with interdisciplinary approach to translation as one of the forms of the intended result of interdisciplinary operation in line with balancing, accommodation, synthesis or making connections between multiple perspectives [17-20].

Thus, translation as an intralingual transformation process inherent in communication of diverse disciplinary groups facilitates the co-creation of new interdisciplinary meaning and achievement of shared goals. In doing so, multidisciplinary team members need to be able to 
comprehend and translate disciplinary languages, ways of knowing and disciplinary methods, and then balance, synthesize and integrate them.

\section{Methods}

There emerged a need of modeling the process of interdisciplinary course design in order to understand at what stages of interdisciplinary team collaboration translation of disciplinary perspectives becomes necessary.

The life cycle of the interdisciplinary collaboration project is comprised of a series of stages from the preparatory phase intended to anticipate communication risks between different disciplinary groups of experts to the creation and implementation of the interdisciplinary communication course. The preparatory stage of the collaboration in focus was highly important and predetermined the workability of the following activities. It lasted for 3 months during the course of discussions on the integration of two different courses between the language and communication instructors and the experts in economics and management, finance, organizational behavior, social psychology and pedagogy.

The interdisciplinary course under consideration seeks to integrate language, communication and subject-specific knowledge in the field of business and management with the purpose of developing the core communicative competence of bachelor students across the disciplines. Language and communication instructors find a significant emerging potential in the integration of language and communication courses with business and management disciplines; therefore, this argument needed to be properly formulated and explained to business and management faculty in the beginning of the project to bring about the collaboration process.

At the preparatory stage of the interdisciplinary course design, two courses to be integrated were identified: 'Language and Communication skills in English: subject-specific' course and 'Business Plan: Term paper' course. Although both courses are taught separately, they are built around the common teaching agenda. The business course provides the context for the communicative competence development while the language and communication course facilitates the communication of the acquired knowledge and verbalization of solutions to the identified business problems.

To justify the hypothesis, language and communication team members designed the model of translation of learning goals, objectives and outcomes of the neighboring course from one disciplinary language into another as an instrument to enable course designers to enter into an interdisciplinary dialogue with experts of a different professional area (Figure 1).

The first step of the translation process implied disciplinary or professional reading of 'Business Plan. Term Paper' course syllabus in order to identify the potential capacity for the communicative competence development. The analysis revealed that half of the target skills intended for development in the business course is intertwined with the communicative efficiency of students (Table 1).

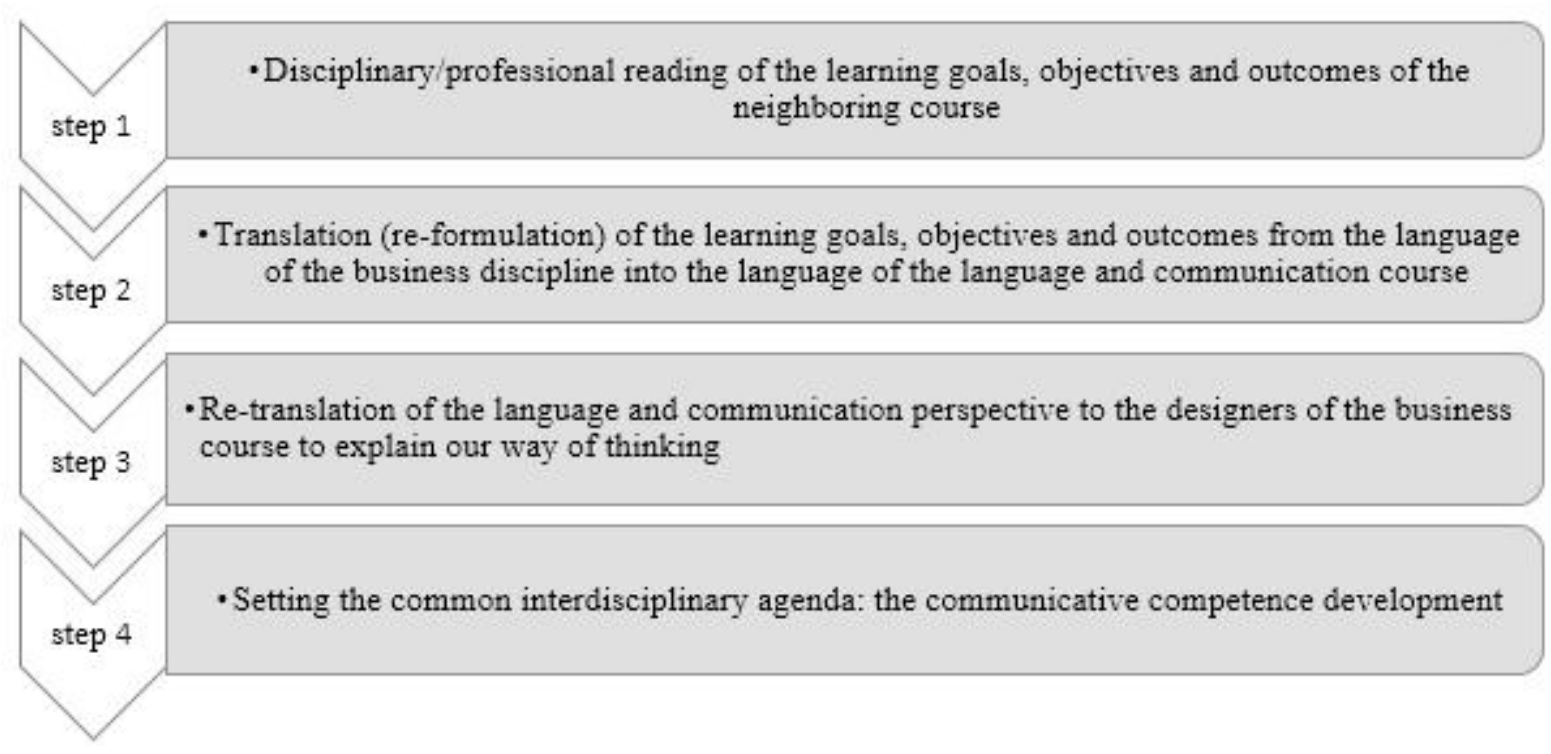

Figure 1. The process of translation of learning goals, objectives and outcomes from a disciplinary language into another. 
Table 1. The syllabus design of 'Business Plan. Term Paper' course: stage 1

\begin{tabular}{|c|c|}
\hline Items of analysis & Text of the syllabus \\
\hline Stage focus & The goal and procedure of writing the term paper. Formulation of a business idea and goals of the project. \\
\hline The learning outcome & The written outline (description) of the process of creating a business plan. \\
\hline Skills to be developed & $\begin{array}{l}\text { - } \quad \text { to identify a business idea and design a business canvas } \\
\text { - } \quad \text { to select, systematize and analyze information from relevant sources of information } \\
\text { - } \quad \text { to formulate a business idea } \\
\text { - } \quad \text { to set and maintain contact with a non-academic stakeholder of the project group } \\
\text { to interpret data provided by business stakeholders }\end{array}$ \\
\hline
\end{tabular}

Table 2. Translation (re-formulation) of the statement from the language of the business course into the language of the language and communication course

\begin{tabular}{|c|c|c|}
\hline \multirow{2}{*}{$\begin{array}{l}\text { 'Business Plan. } \\
\text { Term Paper' course }\end{array}$} & \multicolumn{2}{|c|}{ 'Language and Communication Skills in English: subject-specific' course } \\
\hline & Items for analysis & Communication skills \\
\hline $\begin{array}{l}\text { the skill: } \\
\text { 'Students can contact a } \\
\text { non-academic stakeholder } \\
\text { of the project group' }\end{array}$ & $\begin{array}{l}\text { - 'to contact': students can initiate and } \\
\text { maintain the process of } \\
\text { communication for decision-making } \\
\text { 'non-academic stakeholder': students } \\
\text { can communicate with specific } \\
\text { audience } \\
\text { 'project group': students can } \\
\text { communicate when working in a } \\
\text { group of peers }\end{array}$ & $\begin{array}{l}\text { - To be able to interview a business owner to better } \\
\text { understand a business idea students need to: } \\
\text { discuss sensitive issues to avoid cultural bias and } \\
\text { errors } \\
\text { - } \quad \text { design and sequence questions for the interview } \\
\text { - } \text { set rapport with a business owner and maintain } \\
\text { communication process } \\
\text { - clarify the expectations of an interviewee }\end{array}$ \\
\hline
\end{tabular}

The syllabus analysis showed that for successful achievement of stage 1 of the business course, students need to be able to communicate in oral and written forms with academic and business audiences.

This fact necessitated the translation of the skills outlined in 'Business Plan. Term Paper' course from the language of the business and management disciplines into the language comprehensible to the language and communication instructors. The sets of the learning objectives, skills and learning outcomes at all stages of the business course implementation were analyzed. We observed that the majority of 'Business Plan. Term Paper' course goals and objectives entail the ability and skills of students to effectively communicate the learning outcomes, for example, students need to be able to communicate effectively in a group of peers as well as with a business owner in order to succeed in the business plan project. However, there are no explicitly written objectives of the communicative competence development in the syllabus of the 'Business Plan. Term Paper' course.

To illustrate the intralingual translation process (Fig.1, step 2) from one disciplinary language into another, we address one of the skills from the syllabus 'Business Plan. Term Paper' course designed by business instructors and demonstrate the difference in perception of the concepts between communication instructors and business instructors caused by their dissimilar areas of professional expertise (Table 2). The statement of the skill 'to set and maintain contact with a non-academic stakeholder of the project group' was parsed into three significant elements from communication perspective: 'to contact', 'non-academic stakeholder' and a 'project group' which convey their own self-sufficient meanings in terms of communication.

For communication instructors 'to contact somebody' purports a series of subsequent acts of communication from initiating, setting rapport with a subject and maintaining it till its finalization. The concept "a non-academic stakeholder" is also addressed differently, because from a communication perspective it implies specific audience and can necessitate the shift between registers and the choice of specific linguistic means in order to achieve the goal of communication. Finally, a 'project group' suggests collaboration of a few participants who are aware of the rules of group dynamics and can do group work with peers.

Thus, this skill of the business course was translated into the language of the communication course, inducing the course designers to specify a set of sub-skills to be developed such as to discuss sensitive issues to avoid cultural bias and errors, design and sequence questions for the interview with a non-academic stakeholder, set rapport with a business owner and maintain communication process, clarify the expectations of an interviewee.

At the following stage (Fig.1, step 3), we re-translated the language and communication perspective to business and management colleagues in order to explain the vision on the integration of the courses.

The process of translation of the neighboring course 
learning goal, objectives and outcomes served the main purpose - to facilitate interdisciplinary communication among the diverse members of collaboration team who needed to reach agreement on the common interdisciplinary agenda of developing the communicative competence of students across the courses (Fig.1, step 4).

\section{Results}

The multidisciplinary team collaboration project disclosed the communication complexities identified in the previous studies as follows: the lack of trust among members of team, differences in motivation for participating in the interdisciplinary project, as well as values shaped by peculiar areas of expertise and professional habits of mind. The language and communication team members who initiated the collaboration received numerous critical responses such as 'I do not understand the point why and how we can integrate business courses with language and communication courses'. The colleagues of business and management areas of knowledge perceived and some of them still tend to perceive language and communication instructors as the invaders into their disciplinary areas, who provide students with not well-informed views.

The model of translation of learning goals, objectives and outcomes enabled the language and communication instructors to better understand the integration principle of both courses and articulate the language and communication perspective in the process of interdisciplinary collaboration. It proved to be a working instrument to analyze the syllabus of the business course and identify a potential capacity for integration with the language and communication course. By crossing the boundaries between language, communication and business disciplines and making connections across these two fields of knowledge, students learn to verbalize and communicate their thoughts and ideas more efficiently. The language and communication course aims to help students formulate and explain the identified business problems, justify plausible solutions, build strong arguments, ask focused questions, choose an appropriate register in the academic and business settings, communicate in a multicultural environment and, on the top of it, develop their interdisciplinary thinking skills through language and communication context.

Simultaneously with the collaboration with "Business Plan. Term Paper" instructors, the language and communication course designers had systematic professional formal and informal talks with experts of different disciplinary backgrounds: Economics, Management, Mathematics, Financial Management and Business Ethics. The communication with experts who are not directly involved in the process of the interdisciplinary course design but who have their detached professional opinions on the interdisciplinary idea confirmed the value of the interdisciplinary initiative. It strengthened our positive attitude to the communication process because we, language and communication instructors, need to explain to business and managements colleagues that we share a demanding task to implement in collaboration: to develop the communicative competence of students across diverse courses.

That broader multidisciplinary team has justified the hypothesis of what is to be controlled to empower the collaboration process and trust among interdisciplinarians: the language of collaboration that is easily recognized by all participants and a precise formulation of the disciplinary perspective how the language and communication course contributes to successful achievement of learning goals and objectives of the business course.

\section{Discussion and Conclusions}

This study sought for evidence whether translation as a social practice can aid the members of a multidisciplinary team in their communication process for the purpose of designing an interdisciplinary course.

The complexities of communication in the process of interdisciplinary collaboration have taken us to the importance of translating one disciplinary perspective into the language of another disciplinary perspective. We performed the translation process as intralingual transformation of meanings inherent in diverse disciplinary contexts with the purpose to create a new interdisciplinary meaning and achieve the shared goals. Our language of collaboration has resulted from our mutual efforts of translating from one disciplinary language into another.

The complexity which stays in the focus of collaboration is to overcome the skepticism from the other discipline course designers: why to collaborate with language and communication course and how language and communication course can contribute meaningfully to the specific business courses. The interdisciplinary collaboration project has led us to the conclusion for team members to formulate and voice their aims, ideas and intentions transparently to the neighboring course designers and even broader audiences.

Design and implementation of interdisciplinary courses and programs in multidisciplinary teams of experts can be effective if all members of a team collaborate across disciplines in order to discuss and achieve the common interpretation of the communicative competence and facilitate the development of communication skills across the disciplines. In this study we contributed to the advancement of the idea that through language and communication disciplinary perspective, students will understand the broader context, in which the business 
course is positioned, and learn to verbalize and communicate the research process related to developing a business course agenda in an interdisciplinary way. The interdisciplinary course enables students to make connections across the disciplines, use language and communication to better process newly learned information and become more flexible and creative in problem solving.

We argue that at the preparatory stage of an interdisciplinary course design, the model of translation is efficient and can facilitate the communication process of multidisciplinary team members on the way to define the shared goals and common agenda of a project. This study contributes to further research to investigate the process of translation and factors of successful interdisciplinary communication.

The process of communication will enable multidisciplinary team members to achieve the intended goals faster as they know what makes them different in terms of ways of communication and how to complement each other with the diversity of their professional cultures, skills and competences.

\section{REFERENCES}

[1] S. Eigenbrode, M. O'Rourke, J. Wulfhorst, D. Althoff, C. Goldberg, A. Edmondson, J. Dillon, \& K. Roloff. Three perspectives on team learning, The Academy of Management Annuals, Vol.1, No.1, 269-314, 2007

[2] J.Cummings, S. Kiesler, R. Zadeh \& A. Balakrishnan, A. Group heterogeneity increases the risks of large group size: A longitudinal study of productivity in research groups, Psychological Science, Vol. 24, No. 6, 880-890, 2013

[3] J.Nancy, Cooke, L. Hilton, Editors. enhancing the effectiveness of team science, Committee on the Science of Team Science. Board on Behavioral, Cognitive, and Sensory Sciences; Division of Behavioral and Social Sciences and Education; National Research Council. The National Academies Press. Online available:http://www.nap.edu/catalog.php?record_id=1900 7

[4] H.Dielman. Transdisciplinary hermeneutics: a symbiosis of science, art, philosophy, reflective practice, and subjective experience, Issues in Interdisciplinary Studies, No.35, $170-188,2017$

[5] M.Keestra, M.Multi-level perspectives on interdisciplinary cognition and team collaboration: challenges and opportunities, Issues in Interdisciplinary Studies, No. 35, 113-120, 2017

[6] W.Lash-Marshall, Ch. Nomura, K. Eck \& P. Hirsch P.D. Facilitating collaboration across disciplinary and sectoral boundaries: application for a four-step strategic intervention, Issues in Interdisciplinary Studies, No. 35, 200-220. 2017

[7] K.Locker. The challenge of interdisciplinary research,
International Journal of Business Communication, Vol. 31, No. 2, 137-151, 1994

[8] J.Welsh. All too human: conflict and common ground in interdisciplinary research and complex problem-solving, Issues in interdisciplinary studies, No. 35, 88-112, 2017

[9] V.Boix Mansilla, M. Lamont \& K. Sato. Shared cognitive-emotional interactional platforms: markers and conditions for successful interdisciplinary collaboration, Science, Technology and Human Values, Vol. 41, No. 4, 571-612, 2015

[10] R.Szostak.Stability, instability, and interdisciplinarity, Issues in Interdisciplinary Studies, No. 35, 65-87, 2017

[11] D.Stokols, M. Shalini, P. Richard, L. Kara Hall \& B. Taylor. The ecology of team science: understanding contextual influences on transdisciplinary collaboration, American Journal of Preventive Medicine, No. 35(2S), 96-115, 2008

[12] B.Czarniawska, G.Sevón. Translating organizational change, de Gruyter, Berlin, 1996

[13] D.Nicolini. Medical innovation as a process of translation: A case from the field of telemedicine, British Journal of Management, Vol. 21, No. 4, 1011-1026, 2010

[14] A.Wæraas, J.Nielsen. Translation theory 'translated': three perspectives on translation in organizational research, International Journal of Management Reviews, Vol. 18, No. 3, 236-270, 2016

[15] B. Latour. The powers of association. In: J. Law (ed.) Power, Action and Belief, Routledge, London, 1986.

[16] P.Lecomte. Why language matters, EFMD Global Focus, Vol. 3, No. 12, 68-71, 2018

[17] S.Nikitina. Three strategies for interdisciplinary teaching: contextualising, conceptualising, and problem-solving. Project Zero: Harvard Graduate School of Education, 2002

[18] M.Miller, V.Boix Mansilla. Thinking across perspectives and disciplines, Interdisciplinary Studies Project, Project Zero: Harvard Graduate School of Education, 2004. Online available

from https://pdfs.semanticscholar.org/01e0/a87b220909ad8475f 1733471ba357e486f63.pdf

[19] H.Gardner. Five Minds for the Future, Harvard Business School Press, Boston, Mass, 2006

[20] V. Boix Mansilla, E. Duraising. Targeted assessment of students' interdisciplinary work: an empirically grounded framework proposal. Journal of Higher Education, Vol. 78, No. 2, 215-237, 2007 